\title{
Friday Exception Scheduling in Transit Systems: An Exploratory Analysis When Data Are Limited
}

\author{
Michael D. Benson, Robert B. Noland \\ Alan. M. Voorhees Transportation Center \\ Rutgers, The State University of New Jersey
}

\begin{abstract}
Most transit agencies operate the same schedule Monday through Friday, except on holidays. Recent work suggests that agencies potentially could save money by operating different schedules on Friday. This research paper aims to identify factors associated with different ridership patterns on Friday, especially when limited data are available. Ridership data for seven bus routes serving Newark, New Jersey, were analyzed, along with characteristics of the routes and areas they serve. These data were limited in that they were provided as a PDF file and were for one month only. Land uses associated with commuting, specifically those with a mix of high residential density and employment density, were found to have different ridership patterns on Friday. A three-part screening process is outlined, looking at the base level of weekday ridership, service frequency, and the residential and employment land uses served. Based on this, two routes serving Newark were identified for which an alternative schedule potentially could be implemented on Friday. This screening process will be useful for transit agencies with limited data resources and that may benefit from Friday exception scheduling, when it is feasible to implement.
\end{abstract}

\section{Introduction}

Recent research suggested that New York City Transit could save \$13 million per annum by operating different bus schedules on Friday, due to different ridership demands compared to other weekdays (Lu and Reddy 2012). However, not all bus routes show a consistent decrease in ridership on Friday. A one-week snapshot of data from NJ TRANSIT showed that of the 38 bus routes that serve Newark, there was a median reduction of 3.1 percent in trips on Friday compared to the average for Tuesday through Thursday, and that only 28 routes showed an overall decrease in trips on Friday. Changes in the number of trips on Fridays varied from a reduction of 17 percent to an increase of 21 percent. 
This paper further explores the issues identified by Lu and Reddy (2012) by investigating the underlying route, demographic, land use, and other factors associated with different ridership patterns on Friday. The aim is to provide transit agencies with a simple screening technique that is usable in the absence of detailed ridership data to identify routes with the greatest potential for operating different schedules on Friday (exception schedules), which potentially could lead to significant cost savings.

\section{Background}

Most transit agencies operate the same schedules Monday through Friday, with different schedules on Saturday, Sunday, and holidays. However, exception schedules often are run for special events or on the Friday before a holiday weekend. For example, NJ TRANSIT operated extra rail and bus services for the 2014 Super Bowl, which was held in northern New Jersey (NJ TRANSIT 2014), and runs an "Early Getaway" service, with extra trains on the Friday afternoon preceding major holiday weekends, including Memorial Day and Labor Day (NJ TRANSIT 2012, NJ TRANSIT 2014(a)).

Lu and Reddy (2012) identify three potential factors that may lead to different transit ridership patterns on Friday. First, people may not travel at all on Friday if they work parttime or if they choose to work at home. Second, people may leave work earlier on Friday compared to other weekdays. Third, people may engage in other activities after work on Friday, such as shopping or recreation. In each case, people will travel at a different time on Friday compared to other weekdays (or may choose to not travel at all), and the transit agency could choose to respond differently-for example, by not strengthening service in the PM peak as is routinely done on other weekdays or by running extra late-night services.

A report for the UK Department for Transport identified a variety of different flexible working practices, in particular, part-time (working fewer than 30 hours per week), flextime (varying start and finish times), and compressed hours (working a full workweek over a shorter time period, for example, 4 10-hour days or a 9-day fortnight) (IFF Research 2013). Studies by the Bureau of Labor Statistics estimated that 27.5 percent of workers in May 2004 had flexible schedules ("that allowed them to vary the time they began or ended work") (Bureau of Labor Statistics 2005) and that working at home and shift working varies by occupational group. Whereas shift workers may have different travel patterns compared to employees who work the traditional 9-to-5, they are unlikely to have any flexibility in changing their shift start and end times (Torpey 2007). This suggests that flexible work trends may result in significant changes in ridership on Friday, as this is often the day that employees choose to not work or to leave early. Also, identifying large clusters of employees in industries associated with flexible working practices may help identify the routes that experience the largest changes in ridership on Friday. Analysis of National Household Travel Survey (NHTS) data also showed that flexibility in work arrival times varied by household income and gender (Federal Highway Administration 2012).

Other factors that may influence ridership patterns on Friday include car ownership (Roorda, Saneinejad, and Miller 2007), areas where a high percentage of people do not 
work (unemployed, students, retired) due to fewer commute trips, and the length of commute (Metz 2008; Mokhtarian and Chen 2003).

The objective here is to extend the work of Lu and Reddy (2012) by investigating how these factors may affect Friday ridership. As part of this analysis, a technique for screening potential routes for further investigation of Friday exception scheduling was developed, which may be especially useful for agencies without sufficient data.

\section{Methodology and Data}

Seven routes were selected from the 38 that serve Newark and were considered representative of the types of route operated by agencies serving large urban areas. These include a mix of urban-to-suburban, intra-urban, and urban-to-urban routes that serve a variety of trip purposes and destinations, including local and regional employment centers, retail destinations, schools, colleges, and healthcare and recreational facilities. The service frequency, hours of service, and average number of daily unlinked trips also varied substantially across these routes. A map of the routes and a table summarizing their key characteristics are provided in Figure 1 and Table 1.

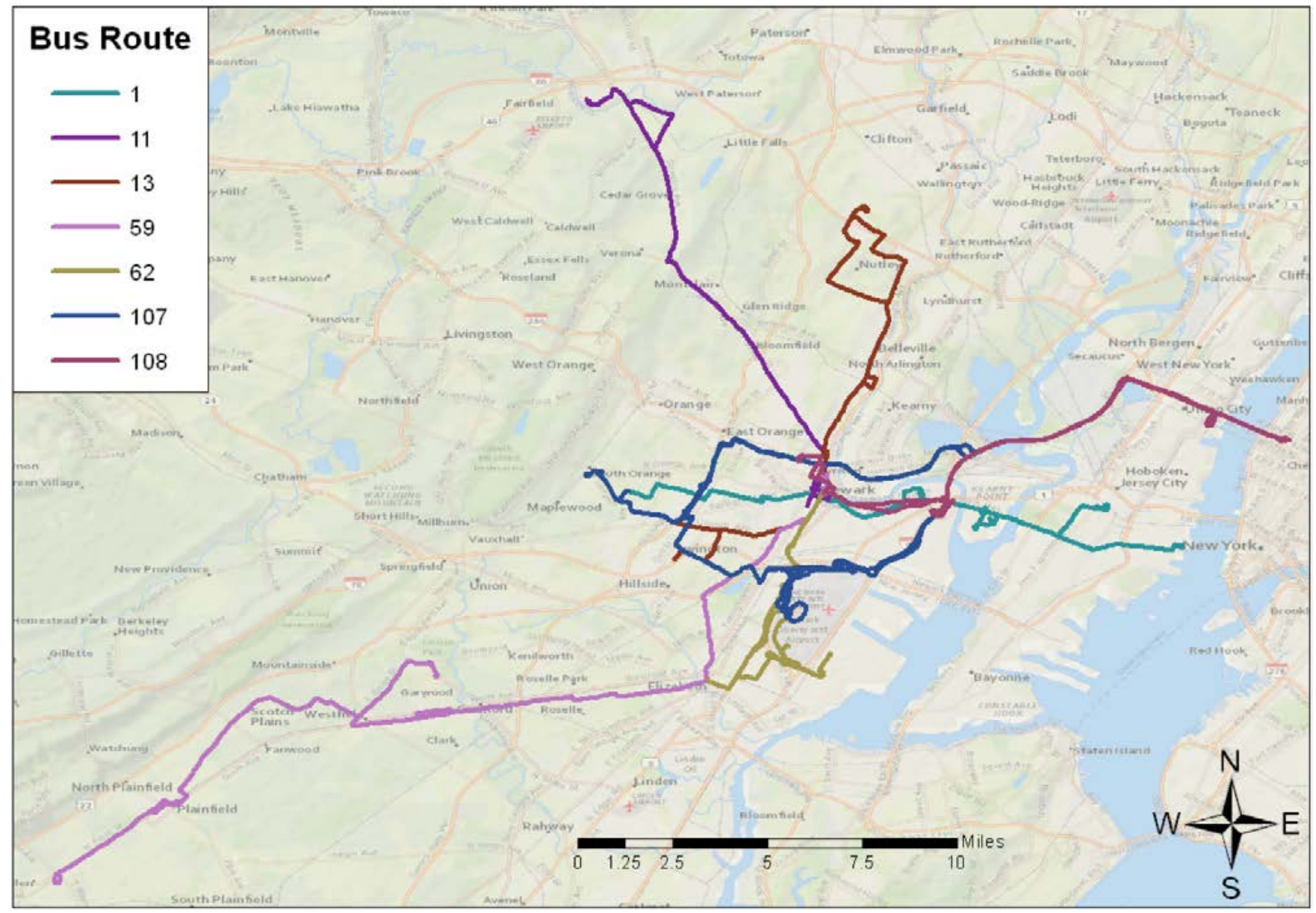

FIGURE 1. NJ TRANSIT route map (NJ TRANSIT 2013b) 
TABLE 1. Service Characteristics

\begin{tabular}{|c|c|c|c|c|c|c|c|c|c|c|c|c|}
\hline Route & Terminals & $\begin{array}{l}\text { Other Major } \\
\text { Destinations } \\
\text { Served }\end{array}$ & $\begin{array}{l}\text { Route } \\
\text { Length } \\
\text { (miles) }\end{array}$ & $\begin{array}{l}\text { AM Peak } \\
\text { Frequency } \\
\text { (Buses per } \\
\text { Hour per } \\
\text { Direction) }\end{array}$ & $\begin{array}{l}\text { Inter-Peak } \\
\text { (Buses per } \\
\text { Hour per } \\
\text { Direction) }\end{array}$ & $\begin{array}{l}\text { PM Peak } \\
\text { (Buses per } \\
\text { Hour per } \\
\text { Direction) }\end{array}$ & $\begin{array}{l}\text { Off-Peak } \\
\text { (Buses per } \\
\text { Hour per } \\
\text { Direction) }\end{array}$ & Hours of Service & $\begin{array}{l}\text { Average } \\
\text { Running } \\
\text { Time } \\
\text { (h:mm) }\end{array}$ & $\begin{array}{l}\text { Average } \\
\text { Daily } \\
\text { Trips } \\
\text { (rank) }^{\mathrm{a}}\end{array}$ & $\begin{array}{l}\text { Minimum } \\
\text { Daily Trips }\end{array}$ & $\begin{array}{l}\text { Maximum } \\
\text { Daily Trips }\end{array}$ \\
\hline 1 & $\begin{array}{l}\text { Newark (Ivy Hill)-Jersey City } \\
\text { (Exchange Place/Journal Square) }\end{array}$ & Kearny & 7.7 & 13 & 8 & 13 & 3 & $5: 30 \mathrm{AM}-3: 30 \mathrm{AM}$ & $0: 44$ & $\begin{array}{l}15,200 \\
(2)\end{array}$ & 11,000 & 16,000 \\
\hline 11 & $\begin{array}{l}\text { Newark (downtown)- } \\
\text { Willowbrook }\end{array}$ & Montclair & 14.3 & 4 & 2 & 2 & 1 & 5:30 AM-9:30 PM & $1: 03$ & $\begin{array}{c}3,100 \\
(19)\end{array}$ & 1,900 & 3,800 \\
\hline 13 & Irvington-Clifton & & 13.6 & 8 & 8 & 8 & 3 & 4:45 AM- 1:45 AM & $0: 51$ & $\begin{array}{l}15,500 \\
(1)\end{array}$ & 10,300 & 16,600 \\
\hline 59 & Newark (downtown)- Plainfield & & 24.2 & 4 & 5 & 3 & 1 & 6:00 AM- 9:00 PM & 1:13 & $\begin{array}{c}5,500 \\
(11)\end{array}$ & 4,000 & 6,000 \\
\hline 62 & Newark (Penn Station)- Elizabeth & Newark Airport & 12.3 & 4 & 4 & 4 & 3 & $24 \mathrm{hrs}$ & $0: 34$ & $\begin{array}{c}5,500 \\
(10)\end{array}$ & 4,000 & 5,900 \\
\hline 107 & $\begin{array}{l}\text { South Orange-New York City } \\
\text { (Port Authority Bus Terminal) }\end{array}$ & Newark Airport & 23.1 & 8 & 2 & 6 & 2 & $5: 00$ AM-1:00 AM & $0: 57$ & $\begin{array}{c}3,400 \\
(17)\end{array}$ & 2,500 & 3,600 \\
\hline 108 & $\begin{array}{l}\text { Newark (Penn Station)-New } \\
\text { York City (Port Authority Bus } \\
\text { Terminal) }\end{array}$ & Union City & 14.9 & 1 & 1 & 1 & 1 & $\begin{array}{l}\text { 5:00 AM-12:00 } \\
\text { midnight }\end{array}$ & $0: 44$ & $\begin{array}{l}1,300 \\
(29)\end{array}$ & 800 & 1,400 \\
\hline
\end{tabular}

${ }^{a}$ Rank refers to average daily number of unlinked trips for NJ TRANSIT buses serving Newark. Of the 38 routes that serve Newark, Route 13 serves the most trips and Route 1 the second most. Sources: NJ TRANSIT 2013; NJ TRANSIT 2013C 
NJ TRANSIT provided data for the number of unlinked trips for every weekday in February (20 days total) by route. These data were exported from their monitoring system in PDF format and were based on farebox registrations (when a passenger boards a bus and either buys a ticket or shows a pass or ticket, this is registered in the system; total registrations for each run are then recorded by operator log-on time). The data were then converted to a more usable format, cleaned, and checked. NJ TRANSIT (2013a) also provided a GIS layer with all of its bus stops in New Jersey. All of the stops served by the seven routes were selected, and a quarter-mile buffer was drawn around each stop (the maximum distance passengers are expected to walk to a bus stop [NJ TRANSIT 2010; Kittelson \& Associates, Inc., et al 2013]). Other data were then spatially joined to each bus stop based on this buffer and summarized at the route level. These included population and employment data (U.S. Census Bureau 2010, 2011); the location and types of schools, colleges, and hospitals (New Jersey Geographic Information Network 2007, 2008, 2012); length of commute (U.S. Census Bureau 2011); car ownership and household income (U.S. Census Bureau 2011); and the non-working-age population (U.S. Census Bureau 2010). Land use data were taken from the New Jersey Department of Environmental Protection's Land-Use/Land-Cover dataset (New Jersey Department of Environmental Protection 2010), which provides information on land uses collected from color infrared imagery and other data sources. Route characteristics were taken from General Transit Feed Specification (GTFS) data (NJ TRANSIT 2013c) and published timetable information (NJ TRANSIT 2013). These data were supplemented with site visits.

\section{Issues with Ridership Data}

As noted, the NJ TRANSIT ridership data were in a format that made it time-consuming to extract and analyze. Whether other transit agencies can access only PDF reports of their data is not known, but this seems to be the case for NJ TRANSIT and makes analysis problematic. There were several other limitations with this data. First, there was a holiday (Presidents' Day) during this period. Trips on this Monday were considerably lower than other Mondays, so this day was excluded from the analysis. The number of trips the week before and the remainder of the week following Presidents' Day was similar to the other weeks in February, so these days were not excluded, and it was not considered a significant limitation of the data.

Second, the trip data were time-stamped based on when the operator logged on to the system at the start of the route, not when a passenger actually purchased a ticket. This means that when analyzing the data, the peak travel times are earlier than what would normally be considered the peak. Given that the time between when the driver logs on and when the route starts is approximately one hour, peak travel times based on the timestamp are potentially one hour earlier than the actual peak travel time. When analyzing the data, all of the times recorded had been shifted appropriately. This is not considered a significant limitation, as the trip patterns still will be the same.

Third, only the total number of unlinked trips was recorded for each route, not the number of trips between particular stops or linked trips made by passengers. This means that only route-level characteristics could be analyzed and not the characteristics of individual 
stops, passengers, or journeys that included transfers. While this is a limitation, given the number of trips, this level of aggregation may be necessary to identify overall trends.

Fourth, as the data covered only one month, it was not possible to consider seasonal variations in trips. However, as February is a month without a significant holiday that would markedly affect ridership, this is not considered a significant limitation. There also were no significant weather events that would have changed ridership patterns.

Available survey data instead of trip data were explored to assess suitability. However, it is unusual for data to be collected for the purpose of assessing variations across days of the week; most data collection excludes Friday, as traffic on this day is considered "abnormal" (Department for Transport [UK] 2014), and it is rare for data collection to take place over a sufficiently long period (more than two weeks) to allow longer-term activity patterns to be identified (Axhausen et al. 2002), such as nine-day fortnights. NJ TRANSIT tends to conduct on-board survey data collection only for specific studies; no survey data were available that would be suitable for this research.

NHTS data also were explored, as these are available broken down by day of the week and time of day. There are more trips on Friday than any other day across all modes: 15.4 percent of trips are made on Friday, based on calculations done with the 2009 NHTS data (Federal Highway Administration 2011). However, the survey methodology means that the data are not suitable for looking at day-of-week and time-of-day variations in transit use. NHTS does not oversample transit users and, given that they make up such a small percentage of all trips (bus trips accounted for only $1.6 \%$ of total trips in the 2009 survey), breaking these data down further (for example, by day of week and time of day) does not reveal any clear patterns, given the margin of error, and it cannot be done for a specific transit system, let alone for any particular route.

\section{Ridership Patterns During the Week}

Average daily and hourly trips are summarized in Table 2 and Table 3. In general, the patterns are consistent with Lu and Reddy's (2012) findings. For most of the bus routes, the number of trips taken is most similar on Tuesday through Thursday, with the largest differences on Friday. However, one difference is that the increase in evening ridership on Friday observed in New York City is not evident; for each hour between 8:00 PM and 1:00 AM, the day with the lowest number of trips is Friday across all seven routes serving Newark. Other authors have suggested that there may be less transit use at this time on Friday due to the variety of activities being carried out on this day that are more easily accessible by car (Roorda, Saneinejad, and Miller 2007; Clay 1980, 122), so the patterns in ridership in New York City may not be typical of other areas in this respect, given the high level of off-peak transit ridership there. 
TABLE 2. Average Daily Trips by Route

\begin{tabular}{|c|r|r|r|r|r|c|}
\hline \multirow{2}{*}{ Route } & \multicolumn{5}{|c|}{ Average Trips } & \multirow{2}{*}{$\begin{array}{c}\text { Day with Lowest } \\
\text { Average Trips }\end{array}$} \\
\cline { 2 - 6 } & Monday & Tuesday & Wednesday & Thursday & Friday & Friday \\
\hline 1 & 15,165 & 15,287 & 15,591 & 15,785 & 14,281 & Monday \\
\hline 11 & 3,159 & 3,238 & 3,177 & 3,287 & 3,169 & Friday \\
\hline 13 & 15,523 & 15,708 & 15,490 & 15,876 & 14,893 & Wednesday \\
\hline 59 & 5,357 & 5,499 & 5,297 & 5,790 & 5,311 & Friday \\
\hline 62 & 5,374 & 5,454 & 5,605 & 5,601 & 5,346 & Friday \\
\hline 107 & 3,385 & 3,453 & 3,336 & 3,524 & 3,322 & Friday \\
\hline 108 & 1,282 & 1,340 & 1,349 & 1,262 & 1,125 & Friday \\
\hline Average (All Routes) & 7,035 & 7,140 & 7,120 & 7,304 & 6,778 & . \\
\hline
\end{tabular}

TABLE 3. Average Hourly Trips

\begin{tabular}{|c|c|c|c|c|c|c|}
\hline \multirow{2}{*}{ Route } & \multicolumn{5}{|c|}{ Average Trips } & \multirow{2}{*}{$\begin{array}{l}\text { Day with Lowest } \\
\text { Average Trips }\end{array}$} \\
\hline & Monday & Tuesday & Wednesday & Thursday & Friday & \\
\hline $06: 00-06: 59$ & 2,057 & 2,129 & 2,119 & 2,311 & 2,208 & Monday \\
\hline 07:00-07:59 & 4,328 & 4,384 & 4,375 & 4,458 & 3,822 & Friday \\
\hline 08:00-08:59 & 4,384 & 4,751 & 4,659 & 4,720 & 4,419 & Monday \\
\hline 09:00-09:59 & 3,216 & 3,012 & 2,893 & 3,138 & 2,902 & Wednesday \\
\hline 10:00-10:59 & 2,335 & 2,407 & 2,459 & 2,543 & 2,482 & Monday \\
\hline $11: 00-11: 59$ & 2,367 & 2,267 & 2,120 & 2,211 & 2,135 & Wednesday \\
\hline $12: 00-12: 59$ & 2,489 & 2,419 & 2,392 & 2,287 & 2,636 & Thursday \\
\hline 13:00-13:59 & 2,320 & 2,324 & 2,260 & 2,587 & 2,947 & Wednesday \\
\hline $14: 00-14: 59$ & 2,843 & 2,657 & 2,735 & 2,880 & 2,895 & Tuesday \\
\hline $15: 00-15: 59$ & 3,891 & 4,235 & 4,145 & 4,130 & 3,905 & Monday \\
\hline $16: 00-16: 59$ & 4,201 & 3,844 & 3,939 & 3,914 & 3,628 & Friday \\
\hline 17:00-17:59 & 3,940 & 4,028 & 3,994 & 4,077 & 3,366 & Friday \\
\hline 18:00-18:59 & 2,873 & 2,972 & 2,934 & 2,952 & 2,574 & Friday \\
\hline 19:00-19:59 & 2,153 & 2,027 & 2,225 & 2,277 & 2,112 & Tuesday \\
\hline 20:00-20:59 & 1,438 & 1,482 & 1,530 & 1,557 & 1,257 & Friday \\
\hline 21:00-21:59 & 1,218 & 1,382 & 1,287 & 1,350 & 995 & Friday \\
\hline $22: 00-22: 59$ & 1,003 & 1,058 & 1,114 & 1,053 & 832 & Friday \\
\hline 23:00-23:59 & 692 & 659 & 713 & 825 & 642 & Friday \\
\hline $00: 00-00: 59$ & 386 & 419 & 453 & 398 & 359 & Friday \\
\hline
\end{tabular}

Note: Bold rows are periods with highest number of trips.

Based on estimates using the National Transit Database (NTD), New York City Transit has 76 percent of its vehicles in off-peak service, compared to an average of 45 percent for other large transit agencies, 43 percent for all agencies, and only 17 percent for NJ TRANSIT, suggesting significantly higher off-peak ridership in New York City compared to other areas (Federal Transit Administration 2012). New York City is also likely to attract a larger number of evening leisure trips compared to other urban areas such as Newark, given the quality and variety of activities available. 


\section{Identifying the Potential for Friday Exception Schedules}

Table 4 shows the reduction in total trips on Friday compared to the average for Tuesday through Thursday. All of the routes have fewer trips on Friday, but both the percentage reduction and the reduction in the number of trips vary widely. Routes 1 and 13 show the largest reduction in the number of trips and are likely to be the only routes on which the reduction is sufficiently large to consider changing schedules on Friday.

TABLE 4.

Reduction in Total Trips on Fridays

\begin{tabular}{|c|c|c|c|}
\hline Route & $\begin{array}{c}\text { Average Ridership } \\
\text { (Tue-Thu) }\end{array}$ & $\begin{array}{c}\text { Reduction in } \\
\text { Friday Trips }\end{array}$ & $\begin{array}{c}\text { Percentage Reduction } \\
\text { in Friday Trips }\end{array}$ \\
\hline 108 & 1,317 & -192 & $-14.6 \%$ \\
\hline 1 & 15,554 & $-1,273$ & $-8.2 \%$ \\
\hline 13 & 15,691 & -799 & $-5.1 \%$ \\
\hline 59 & 5,528 & -217 & $-3.9 \%$ \\
\hline 62 & 5,553 & -208 & $-3.7 \%$ \\
\hline 107 & 3,438 & -116 & $-3.4 \%$ \\
\hline 11 & 3,234 & -65 & $-2.0 \%$ \\
\hline
\end{tabular}

Figure 2 and Table 5 show how trips vary by time-period and route on Friday compared to Tuesday through Thursday. Whereas there are large percentage differences in the off-peak on all routes on Friday, the relatively infrequent service on all of the routes suggests that there is limited potential to alter schedules at this time of day given the need to maintain a minimum level of service. Looking at the PM peak, there are significant percentage differences in trips on three of the routes-Route 1 (-17.4\%), Route 13 (-16.7\%), and Route $108(-33.9 \%)$. However, again, given the low number of trips on Route 108 (only 132 trips in the PM peak on Friday), only Routes 1 and 13 should be considered as candidates for which the schedule could be changed on Friday in the PM peak. These routes also both operate at least eight buses per hour per direction in the PM peak, so there is potential to reduce service without this resulting in unacceptably long waiting times for passengers. The changes in the AM peak and inter-peak are generally not as large, although, again, there are reductions of 11.6 percent (498 trips) on Route 1 and 8.2 percent (313 trips) on Route 13 in the AM peak, so there may be some potential to reduce service on these routes at this time. None of the other differences is more than 250 trips (even though, in some cases, this may be a large percentage change), so there is probably limited potential to change the schedule at these times. 
FIGURE 2.

Percentage difference in Friday trips compared to average Tuesday through Thursday trips

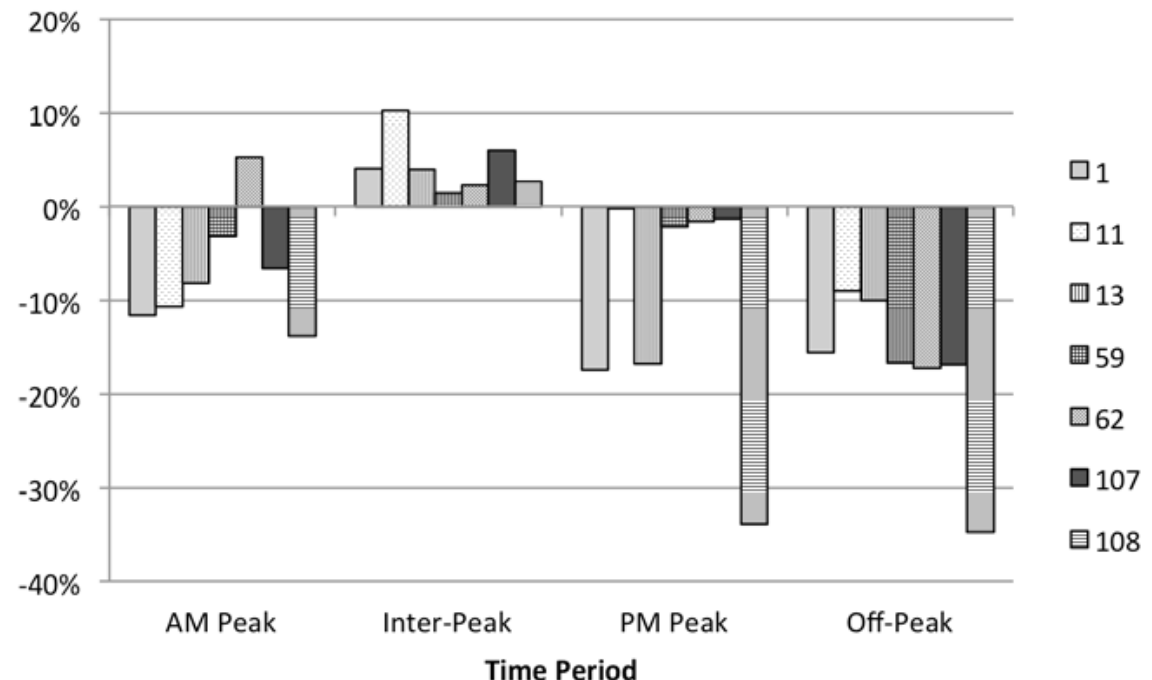

TABLE 5. Change in Friday Trips by Time Period

\begin{tabular}{|c|c|c|c|c|c|c|c|c|}
\hline \multirow{2}{*}{ Route } & \multicolumn{2}{|c|}{ AM Peak } & \multicolumn{2}{c|}{ Inter-Peak } & \multicolumn{2}{c|}{ PM Peak } & \multicolumn{2}{c|}{ Off-Peak } \\
\cline { 2 - 10 } & Change & $\begin{array}{c}\text { Percentage } \\
\text { Change }\end{array}$ & Change & $\begin{array}{c}\text { Percentage } \\
\text { Change }\end{array}$ & $\begin{array}{c}\text { Percentage } \\
\text { Change }\end{array}$ & $\begin{array}{c}\text { Phange } \\
\text { Change }\end{array}$ \\
\hline 1 & -498 & $-11.6 \%$ & 195 & $4.1 \%$ & -607 & $-17.4 \%$ & -286 & $-15.6 \%$ \\
\hline 11 & -78 & $-10.7 \%$ & 105 & $10.2 \%$ & -2 & $-0.3 \%$ & -47 & $-9.0 \%$ \\
\hline 13 & -313 & $-8.2 \%$ & 217 & $3.9 \%$ & -590 & $-16.7 \%$ & -202 & $-10.1 \%$ \\
\hline 59 & -38 & $-3.1 \%$ & 28 & $1.5 \%$ & -28 & $-2.1 \%$ & -70 & $-16.7 \%$ \\
\hline 62 & 43 & $5.3 \%$ & 44 & $2.3 \%$ & -12 & $-1.5 \%$ & -208 & $-17.2 \%$ \\
\hline 107 & -60 & $-6.6 \%$ & 48 & $6.0 \%$ & -10 & $-1.3 \%$ & -97 & $-16.9 \%$ \\
\hline 108 & -42 & $-13.8 \%$ & 10 & $2.6 \%$ & -67 & $-33.9 \%$ & -98 & $-34.7 \%$ \\
\hline
\end{tabular}

Note: Change in Friday trips compared to average for same period for Tuesdays-Thursdays.

As noted above, service frequency is an important consideration, as there is a need to maintain a minimum level of service. Additionally, reducing service frequency likely will have an impact on ridership. TCRP Report 95 found that ridership changes due to changes in service frequencies vary substantially, but the average response to frequency changes (including frequency decreases) approximates a mid-point arc elasticity of 0.5 (Evans et al. 2004). For Route 13, which carries an average of 2,933 trips in the PM peak on Friday and runs 8 buses per hour per direction, this elasticity implies that decreasing this to 6 buses per hour per direction would result in a decrease of 391 trips. However, the research also found that ridership responses to changes in service frequency are greatest when the prior frequency is fewer than three buses per hour (Evans et al. 2004). This suggests an additional criterion for changing service patterns on Friday is that a minimum service frequency of three buses per hour should be maintained. Crowding also may result from a reduction in service frequency. Given that schedules would be changed only on routes that experience less demand on Friday and on routes with at least four buses per hour, it is thought unlikely that this would be a significant issue. However, more detailed trip data, including 
trip origins and destinations and actual time of travel (which were not available), would be necessary to evaluate this further. The need for passengers to be able to connect with other services also may have an impact on service frequency and the timing of services.

There are a number of other relevant considerations in operating different schedules on Friday. There may be customer satisfaction implications; research has found that easy-to-remember departure times are a significant factor in favorable user perceptions of the length of wait for transit service and in increasing ridership (Evans et al. 2004). Operating a different schedule on Friday may make it more difficult to remember departure times. However, Smartphone apps and online journey planners may mean this is less significant than previously believed (see, for example, Sakaria and Stehfest 2013). Minimizing the number of changes in the Friday schedule compared to the schedule for other weekdays also will help to minimize any impact of this. (See NJ TRANSIT 2014b for an example of a schedule with additional services that operate only on certain days.) There will also be costs associated with developing new schedules. These will be specific to each route, but they may be offset by the opportunity to reallocate resources-for example, extending service hours at other times of the week, which may result in increased fare revenue (see, for example, discussion of NJ TRANSIT Route 59 in Evans et al. 2004) or savings in operations and maintenance costs due to fewer route miles being operated. Staffing also may be an issue, as agencies may be limited to the extent they can realize savings in wages by cutting some runs due to labor agreements, and rearranging driver schedules may not be possible.

\section{Land Use and Commuting Patterns}

Previous work by Lu and Reddy (2012) suggested different ridership patterns on Friday may be associated with different commuting patterns on this day. To determine if each route was likely to serve significant numbers of commuters, we examined land use around all of the bus stops on each route. As a commute trip has two ends, an origin at home and a destination at work (or vice-versa), residential and employment land uses were examined. Table 6 summarizes these for each of the routes and shows that the three routes with the most significant difference in trips on Friday are ranked 1st, 3rd, and 4th in terms of the percentage of land along their route that is classified as either residential or employment. Route 59 is ranked 2nd and does not display the same pattern. However, whereas this route has a lot of residential land uses, it does not serve as many employment locations. (It runs from Newark out to the suburbs, serving a number of suburban locations and small towns, including Cranford, Westfield, and Plainfield, with large amounts of residential land but relatively few jobs or large employers.) This suggests that it is the link between residential and employment land uses that is important, as would be expected given the association with commuting. Hence, having a large proportion of residential land use but a relatively small proportion of employment land use, such as Route 59, is not likely to be associated with different ridership patterns on Friday. Similarly, Route 62, which has the largest proportion of land use related to employment but the lowest proportion of residential land, also does not exhibit different ridership patterns on Friday. Residential density also may be a factor, as it is the routes with high percentages of high-density residential land use that display different ridership patterns on Friday. In general, high-density residential land uses would be expected to be correlated with higher levels of transit use (Cervero and Kockelman 1997), so, again, this would be expected. 
TABLE 6. Percentage of Employment and Residential Land Use by Route

\begin{tabular}{|c|c|c|c|c|c|c|c|c|c|c|}
\hline Route & $\begin{array}{c}\text { Employment- } \\
\text { Airport } \\
\text { Facilities }\end{array}$ & $\begin{array}{l}\text { Employment- } \\
\text { Commercial/ } \\
\text { Services }\end{array}$ & $\begin{array}{l}\text { Employment- } \\
\text { Industrial }\end{array}$ & $\begin{array}{l}\text { Total } \\
\text { Employment } \\
\text { Land Use }\end{array}$ & $\begin{array}{l}\text { Residential- } \\
\text { High Density }\end{array}$ & $\begin{array}{c}\text { Residential- } \\
\text { Medium } \\
\text { Density }\end{array}$ & $\begin{array}{l}\text { Residential- } \\
\text { Low Density }\end{array}$ & $\begin{array}{l}\text { Residential- } \\
\text { Rural }\end{array}$ & $\begin{array}{l}\text { Total } \\
\text { Residential } \\
\text { Land Use }\end{array}$ & $\begin{array}{l}\text { Total } \\
\text { Employment } \\
\text { and Residential } \\
\text { Land Use }\end{array}$ \\
\hline 13 & $0 \%$ & $15 \%$ & $8 \%$ & $23 \%$ & $50 \%$ & $12 \%$ & $0 \%$ & $0 \%$ & $62 \%$ & $85 \%$ \\
\hline 59 & $0 \%$ & $11 \%$ & $3 \%$ & $14 \%$ & $21 \%$ & $48 \%$ & $2 \%$ & $0 \%$ & $71 \%$ & $85 \%$ \\
\hline 108 & $21 \%$ & $7 \%$ & $5 \%$ & $33 \%$ & $33 \%$ & $12 \%$ & $1 \%$ & $0 \%$ & $46 \%$ & $79 \%$ \\
\hline 1 & $0 \%$ & $21 \%$ & $11 \%$ & $32 \%$ & $45 \%$ & $1 \%$ & $0 \%$ & $0 \%$ & $46 \%$ & $78 \%$ \\
\hline 11 & $0 \%$ & $16 \%$ & $4 \%$ & $20 \%$ & $22 \%$ & $23 \%$ & $9 \%$ & $1 \%$ & $55 \%$ & $75 \%$ \\
\hline 107 & $0 \%$ & $22 \%$ & $17 \%$ & $39 \%$ & $29 \%$ & $0 \%$ & $0 \%$ & $0 \%$ & $29 \%$ & $68 \%$ \\
\hline 62 & $20 \%$ & $14 \%$ & $8 \%$ & $42 \%$ & $13 \%$ & $0 \%$ & $0 \%$ & $0 \%$ & $13 \%$ & $55 \%$ \\
\hline
\end{tabular}

Residential Classifications:

High Density: High-density single units or multiple dwelling units on 1/8-1/5 acre lots. This includes single-unit residential areas of more than five dwellings per acre, residential area of two and three family homes, row houses and garden apartments up to three stories high, and residential areas comprising condominiums, apartment complexes, and towers of four stories or more.

Medium Density: Single residential units on $1 / 8-1 / 2$ acre lots.

Low Density: Single residential units on $1 / 2-1$ acre lots.

Rural: Single residential units on lots between 1 and 2 acres. Despite the name, this includes estates or modern subdivisions with large lot sizes having a density of less than $1 \mathrm{dwelling}$ unit per acre. (New Jersey Department of Environmental Protection 2007) 
Population and employment along each of the routes show similar but not identical patterns. This may be because Census data were taken from block groups that overlapped with areas served by bus stops on each route and, hence, may include employment or residential areas that are outside of the quarter-mile buffer identified as the maximum walking distance to a bus stop. The polygons in the Land-Use/Land Cover dataset are generally smaller than block groups, and hence, spatially, it is likely to be more accurate. Similarly, looking at employment by occupation sector based on those industries that allow flexible working hours (according to Bureau of Labor Statistics 2005) does not show different ridership patterns on Friday. In addition to limitations with the spatial accuracy of the Census data, the limited number of occupation categories recorded by the Census (5) means these data are unlikely to be accurate enough for identifying clusters of employees with flexible hours.

Route 62 serves the airport and was observed to be used by a large number of airport employees and few airline passengers. These employees are less likely to have flexibility in the hours they work due to their large amount of shift work. Route 107 also serves the airport. These two routes show relatively low reductions in total trips on Friday compared to the average number of total trips for Tuesday through Thursday (reductions of $3.7 \%$ and 3.4\%, respectively) and, in particular, in PM peak on Friday (1.5\% and 1.3\%). Hence, it is possible that routes that serve employers with significant concentrations of shift workers may be more likely to maintain relatively consistent ridership throughout the week, but more data would be required to confirm this.

\section{Other Factors}

Other factors previously identified as likely to be associated with different ridership patterns on Friday, including long commutes, high levels of car ownership, and high household income, were analyzed using the same methodology. However, there was no association between different ridership patterns on Friday and these factors. Similarly, factors identified as likely to be associated with consistent ridership across all weekdays, including Friday, were analyzed, including routes that served significant proportions of education, health, shopping, and leisure trips, and which served significant transit-dependent populations. Again, there was no association between these factors and consistent ridership across all weekdays.

\section{Conclusions}

The focus of this paper has been on attempting to understand why different ridership patterns arise on Friday. They appear to be associated with routes that serve both major residential areas-in particular, high-density residential areas, and employment land uses. This is consistent with variations in Friday ridership patterns being due to changes in work commute trips. Routes used by significant numbers of shift workers do not show these differences in ridership on Friday.

The data obtained for this analysis were very limited. NJ TRANSIT provided only PDF files for a very limited time period and only for a limited number of routes. Whether it has access to more detailed databases is not known, but this is likely not atypical of many transit agencies. Thus, this analysis is focused on providing a screening tool when more 
detailed data on ridership is not readily available. This three-part tool identifies routes where consideration could be given to operating alternative schedules on Friday:

1. Number of trips - sufficient total daily ridership such that a relatively modest reduction in trips (of between about $10 \%$ and $15 \%$ ) on Friday could result in a potential saving of at least one run.

2. Service frequency - the frequency of service during the day and PM peak must be enough that removing or retiming services would not result in unacceptable waiting times for passengers. It would be desirable to maintain a frequency of at least three buses per hour after any alterations have been made to the service.

3. Commuting - identify routes that are heavily used by commuters through looking at the percentage of employment and residential land uses along the corridors served, but consider excluding routes that serve employment centers where large numbers of shift workers are employed.

Applying this to Newark, the two routes that could be considered for operating alternative schedules on Friday are Route 1 and Route 13, although here, as elsewhere, there may be other specific considerations based on staffing or ensuring connections to other transit services that may rule out any changes. These routes showed a reduction in total trips on Friday and, in particular, fewer trips in the AM and PM peaks, so consideration could be given to reducing service in the AM and PM peaks on Friday, but possibly strengthening service during the inter-peak. This could be implemented on a trial basis, with ongoing monitoring to ensure that passenger confusion, crowding, and any reduction in ridership do not cancel out the benefits that could be realized though operating an alternative schedule on Friday. Obviously, other considerations, such as driver scheduling and labor contracts may limit the ability to make scheduling changes.

\section{Acknowledgments}

The authors wish to acknowledge the help of Al Tillotson of NJ TRANSIT for providing bus ridership data.

\section{References}

Axhausen, K. W., et al. 2002. Observing the rhythms of daily life: A six-week travel diary. Transportation, 29: 95-124.

Bureau of Labor Statistics. 2005. The editor's desk: Flexible work schedules in 2004. U.S. Department of Labor, July 5, http://www.bls.gov/opub/ted/2005/jul/wk1/art01.htm.

Cervero, Robert, and Kara Kockelman. 1997. Travel demand and the 3D's: Density, diversity and design. Transportation Research D (Transportation and the Environment), 2(3): 199-217.

Clay, Grady. 1980. Close-Up: How to Read the American City. University of Chicago Press. 
Department for Transport (UK). 2014. TAG Unit M1.2: Data Sources and surveys. Department for Transport. January.

Evans, John E. (Jay), et al. 2004. TCRP Report 95: Traveler Response to Transportation System Changes, Chapter 9: Transit scheduling and frequency. Transportation Research Board.

Federal Highway Administration. 2012. Travel Profile of the United States. http://nhts. ornl.gov/2009/pub/profile_2012.pdf.

Federal Highway Administration. 2011. National Household Travel Survey. http://nhts. ornl.gov/.

Federal Transit Administration. 2012. National Transit Database: RY 2010 Database, April.

IFF Research. 2013. The scope for flexible working in the future. Department for Transport (UK), April.

Kittelson \& Associates, Inc., et al. 2013. TCRP Report 165: Transit Capacity and Quality of Service Manual: Third Edition. Transportation Research Board.

Lu, Alex, and Alla Reddy. 2012. Strategic look at Friday exceptions in weekday schedules for urban transit. Transportation Research Record, 2274(1): 30-51.

Metz, David. 2008. The myth of travel time saving. Transport Reviews, 28(3): 321-36.

Mokhtarian, Patricia L. and Cynthia Chen, 2003. TTB or not TTB, that is the question: A review and analysis of the empirical literature on travel time (and money) budgets. Transportation Research Part A 38(9-10): 643-675.

Neff, John, and Larry Pham. 2007. A profile of public transportation passenger demographics and travel characteristics reported in on-board surveys. American Public Transportation Association, May.

New Jersey Department of Environmental Protection. 2010. Land use/land cover update (7/19/10). July 19, http://www.state.nj.us/dep/gis/lulc07cshp.html.

New Jersey Department of Environmental Protection. 2007. Land use cover classification system: NJDEP Modified Anderson System 2002. January 1, http://www.state.nj.us/ dep/gis/digidownload/metadata/lulc02/anderson2002.html.

New Jersey Geographic Information Network. 2012. Public, private and charter schools point locations.

New Jersey Geographic Information Network. 2008. HSIP New Jersey hospitals point locations.

New Jersey Geographic Information Network. 2007. HSIP New Jersey colleges and universities.

NJ TRANSIT. 2014. Welcome to NJ TRANSIT, the first mass transit Super Bowl! January, http://www.njtransit.com/var/var_servlet.srv?hdnPageAction=SuperBowlTo. 
NJ TRANSIT. 2014(a). Reminder: NJ TRANSIT rail service for Memorial Day weekend May 23-26, 2014. http://www.njtransit.com/sa/sa_servlet.srv?hdnPageAction=ServiceAdjustmentTo\&Adjustmentld $=10978$.

NJ TRANSIT 2014(b). Northeast Corridor rail timetable. May, http://www.njtransit.com/ $\mathrm{pdf} / \mathrm{rail} / \mathrm{r0070.pdf}$.

NJ TRANSIT. 2013. Bus timetables for routes 1, 11, 13, 59, 62, 107, 108. January, http://www. njtransit.com/sf/sf_servlet.srv?hdnPageAction=BusTo.

NJ TRANSIT. 2013(a). NJ TRANSIT bus stop locations, 2013. January.

NJ TRANSIT. 2013(b). NJ TRANSIT currently operating routes, 2013. January.

NJ TRANSIT.2013(c). General Transit Feed Specification Data. March. http://www.njtransit.com/developer.

NJ TRANSIT. 2012. NJ TRANSIT offers "early getaway" service for Labor Day weekend. August, http://www.njtransit.com/tm/tm_servlet.srv?hdnPageAction=PressReleaseTo\&PRESS_RELEASE_ID $=2787$.

NJ TRANSIT. 2010. Service guidelines. May.

Sakaria, Neela, and Stehfest, Natalie. 2013. TCRP web-only document 61: Millennials and mobility: Understanding the millennial mindset and new opportunities for transit providers. Transportation Research Board.

Santos, Adelia, Nancy McGuckin, Hikari Yukiko Nakamoto, Danielle Gray, and Susan Liss. 2011. Summary of travel trends: 2009 National Household Travel Survey. Federal Highway Administration. June.

Torpey, Elka, 2007. Flexible work: Adjusting the when and where of your job. Occupational Outlook Quarterly, Bureau of Labor Statistics, Summer 2007, http://www.bls.gov/ opub/ooq/2007/summer/art02.pdf.

U.S. Census Bureau. 2010. 2010 Decennial Census, Summary File 1.

U.S. Census Bureau. 2011. 2011 American Community Survey 5-Year Average.

\section{About the Authors}

Michael D. Benson (michaeldbenson83@gmail.com) is a Consultant with Systra Ltd. He graduated in May 2013 with a master's degree in City and Regional Planning from the Edward J. Bloustein School of Planning and Public Policy, Rutgers University.

ROBERT B. NOLAND (rnoland@rutgers.edu) is Professor of Transportation Planning and Policy at the Edward J. Bloustein School of Planning and Public Policy and Director of the Alan M. Voorhees Transportation Center at Rutgers University. 